\title{
A Non-Contact Passive Approach for the Effective Collection of Target Explosive Volatiles for Canine Training Aid Development
}

\author{
Sanchez $\mathrm{CL}^{1}$, Huertas $\mathrm{AM}^{1}$, Prada $\mathrm{PA}^{2}$ and Furton $\mathrm{KG}^{{ }^{1}}$ \\ ${ }^{1}$ Florida International University, International Forensic Research Institute, Department of Chemistry and \\ Biochemistry, Miami FL, United States \\ ${ }^{2}$ Texas Tech University, Institute for Forensic Science, Lubbock, TX, United States
}

${ }^{*}$ Corresponding author: Furton KG, Florida International University, Department of Chemistry and Biochemistry, 11200 SW, $8^{\text {th }}$ Street, 33199, E-mail: furtonk@fiu.edu

Citation: Sanchez CL, Huertas AM, Prada PA, Furton KG (2016) A Non-Contact Passive Approach for the Effective Collection of Target Explosive Volatiles for Canine Training Aid Development. J Forensic Sci Criminol 4(2): 205

Received Date: March 17, 2016 Accepted Date: April 27, 2016 Published Date: April 28, 2016

\begin{abstract}
The use of real explosive materials for canine training involves inherent dangers, toxicity risks exposure, and often limited availability of the training material all of which may affect the reliable training of canine teams. For this reason, the development of a training aid suitable for daily operations is beneficial to provide safe and effective explosive detection training that can provide for enhanced detection capabilities. This study presents a non-contact passive approach for the collection of target volatile organic compounds (VOCs) emanating from real explosive materials to be used as potential canine training aids. This will also provide the ability for the creation of new training aids based on the rapid evolution of new explosive threats. Experiments were performed based on previously identified explosive signature volatiles such as 2-ethyl-1-hexanol (2E1H), 2,3-dimethyl-dinitrobutane (DMNB), and 2,4-dinitrotoluene (2,4-DNT). Composition 4 (C4) explosive material was used for the static collection of the 2E1H and DMNB, as well as single based smokeless powder for the collection of 2,4-DNT. The samples were collected in a controlled environment and cotton gauze pads were used as the collection material. A time optimization analysis was conducted for all three target volatiles in time intervals of ranging from 0.5 to 120 minutes. Solid phase microextraction (SPME) was used along with gas chromatographymass spectrometry/electron capture detection (GC-MS/ECD) for extraction and confirmation of target volatiles. The results show that collection of characteristic volatiles are obtained after $15 \mathrm{~min}$ of exposing the gauze pad to $2 \mathrm{E} 1 \mathrm{H}$ and 30 min was optimal for DMNB and 2-4, DNT. Overall, the results demonstrated the possibility to perform static collection of signature VOCs from real explosive materials onto a gauze pad via a non-contact passive method for its potential use as effective canine training aid.

Keywords: Explosives; Training aid; Solid phase micro-extraction; Non-contact passive collection; Canine detection; Gas chromatography-mass spectrometry/electron capture detector

List of abbreviations: SPME: Solid-Phase Microextraction; MS: Mass spectrometry; GC/MS: Gas chromatography-mass spectrometry; GC/ECD: Gas chromatography-electron capture detector; IMS: Ion mobility spectrometry; IED: Improvised explosive device; C4: Composition 4 (plastic explosive); PBX: Plastic bonded explosive; VOCs: Volatile organic compounds; 2E1H: 2-ethyl1-hexanol; DMNB: 2,3-dimethyl-2,3-dinitrobutane;2,4-DNT: 2,4-dinitrotoluene; TNT: 2,4,6-trinitrotoluene; SWGDOG: Scientific Working Group on Dog \& Orthogonal Detector Guidelines; WWII: World War II;PDMS, polydimethylsiloxane; PTEF: Polytetrafluoroethylene; MeOH: Methanol; NIST: National Institute of Standards and Technology; ANOVA: Analysis of Variance
\end{abstract}

\section{Introduction}

The ability to effectively detect trace explosive residues at ports of entry and cargo control points has become a heightened concern in recent years as a result of increased worldwide terrorist activity [1]. Currently, the use of detection canines is still considered to be the most effective tool available to law enforcement personnel for the detection of explosives as they possess highly developed olfactory senses and mobility [2]. The enhancement of explosive canine detection methodologies, particularly for military applications (where dogs are used to detect land mines, ammunitions, and explosives), is a high priority as a result of the rapidly evolving variety of explosive mixtures encountered in the battlefield. Despite the significant advances in analytical instrumentation development, limitations still exist with their use in the field. These systems not only require constant updates of their instrument libraries as the threat from explosives change, but also are designed to detect the actual explosive [3]. This coupled with the fact that many explosives have very low vapor pressures, makes their detection through the transfer of particles and/or vapors challenging and hence these instruments often lack sensitivity and/or selectivity provided by canines [4-9]. Canines like instruments must be properly trained to the ever evolving explosive threats, with required maintenance training sessions to maintain an optimal level of 
performance. Studies have shown that dogs can master 10 or more odors discriminations with relative ease. Results also suggest that this detection requirement does not have detrimental effects on refresher training requirements or the introduction of new odors to the training regimen which can take approximately a week, thus confirming a strong scientific validation for dog detection [10].

In recent decades, canines have been reliably trained to detect explosives, ignitable liquids, narcotics, human scent and the discovered evidence has been successfully submitted in court of law [11-20]. Despite canines' wide potential for detection in many areas, they are most commonly used for explosive detection as a result of the growing threat of terrorism. Canines have been used for explosive detection since World War II as a result of their enhanced mobility and ability to work in different environments, as well as their ability to be quickly trained on target odorants $[17,21,22]$. The foundation of reliable canine detection utilized the fact that while target materials may be physically contained they will still emit volatile organic compounds (VOCs) [23]. These VOCs are chemicals associated with the explosive and provide a reliable indication of the substance. The determination of the chemical compound(s) responsible for a canine alert depends on numerous tests and comparisons of the common compound(s) found in the headspace of different explosive mixtures. Studies in this area play a pivotal role to improve the efficiency of canine training through the use of odor mimics. An odor mimic can be defined as a simulative material that incorporates the dominant VOCs found in the headspace of the actual explosive and can be utilized for biological and instrumental detectors. Often these mimics themselves are non-explosive, non-hazardous and safer to handle than real explosives. Research conducted in this area has identified common dominant odor chemicals emanating from explosives that are in fact, responsible for a canine alert and can be used as an odor mimic [17,18,24-26]. For example; 2,4-dinitrotoluene (2,4-DNT) and 2-ethyl-1-hexanol (2E1H) have been reported as chemicals responsible for canine's alert of cast and polymer based explosives $[17,18,21,22]$. On the other hand, odor signature compounds of smokeless powders and plastic explosives have been identified with instruments such as Solid phase microextraction coupled to Ion Mobility Spectrometry (SPME-IMS) complementing canine detection and allowing for a means of standard calibration between analytical instruments and canines [27-29]. Instrumental evaluation of these compounds has led to improvements of training aid mimics for explosive detection canine teams.

Studies suggest that an entire vapor fingerprint is responsible for canine's detection of an explosive material [23,24]. For this reason, it is crucial to understand the importance of profiling explosive VOCs as numerous volatiles are present including plasticizers, phthalates (such as dimethyl phthalate, diphenyl phthalate, dibutyl phthalate, and diethyl phthalate), 2,4,6 trinitrotoluene (TNT), 2-ethyl-1hexanol $(2 \mathrm{E} 1 \mathrm{H})$, and stabilizers (including diphenylamine, methylcentralite and ethylcentralite). It has been hypothesized that canines use the most abundant volatiles present in the headspace to recognize a substance and those chemicals define the detection odor signature for that substance [8,9,21-31].

In general, an optimal training aid mimic is one that represents no risk to the canine and the handler, is long lasting, difficult to contaminate and requires no special handling conditions. One of the greatest challenges for explosive detection canine teams is the availability of training aids. The challenge lies in the wide range of explosives formulations currently used during military operations throughout the world. In response to this need, the Scientific Working Group on Dog and Orthogonal Detector Guidelines (SWGDOG) has provided best practice guidelines to improve the performance, reliability, and courtroom acceptance of detector dog teams by provide a source of standardization to local law enforcement and homeland security [32]. Currently, there are a variety of explosive training aids being used to train detection canines. However, training dogs for Improvised Explosive Devices (IEDs) and other homemade explosives yield to various challenges as their chemical compositions vary by region, local availability of manufacturing materials and quantities of explosives, fuels and other materials used which results in variations of the available VOCs that allow for canine detection. Hence, there is an unmet need to create on-site training aids when encountered with novel explosive mixtures in deployment operations. For this reason; the development of a canine training aid kit suitable for the ever evolving explosive recipes encountered in military operations is of importance to provide a more robust and efficient pathway to train canines for explosives detection.

This study outlines the creation of training aids using a static collection method which could be used to capture VOCs of these explosives and be used for military detection training. Currently, real explosives are used to perform recurrent maintenance training of canines in the field. However, the transportation and storage of these explosives requires safety precautions that limit the frequency of training. These experiments demonstrate a novel procedure for the collection of target VOCs which circumvent the drawbacks of handling real explosives for canine training and pave the way for the development of training aids from any explosive or explosive residues that could be encountered in military field operations.

\section{Materials and Methods}

\section{Chemical and explosive samples}

Plastic explosive (C4) used for this study was provided by City of Miami Police Department and Metro Dade K9 facility, while single based smokeless powder \# 4896 was purchased from Hodgdon Powder Co., Inc (Shawnee, KS, USA). Calibration chemicals standards used included 2-ethyl-1-hexanol (> 99.6\%) and 2,3-dimethyl-2,3-dinitrobutane, DMNB 98\% from Sigma \& Aldrich (St Louis, MO, USA). 2,4-DNT (1000 $\mathrm{g} / \mathrm{mL}$ in $\mathrm{MeOH}$ ampule) from Accustandard (New Haven, CT, USA). 


\section{Static Collection Method of Explosive Volatiles}

For the static collection of volatiles, triplicates of these materials were placed in $\mathrm{Ball}^{\circledR} 8 \mathrm{oz}$ mason jars. The sorbent collection material was a $100 \%$ cotton 4" x 4" 2-ply gauze pad from DUKAL Co. (Ronkonkoma, NY, USA). Pre-treatment of all collection materials consisted of a direct spike with one milliliter of HPLC grade methanol followed by heating in the oven at a temperature of $105^{\circ} \mathrm{C}$ for one hour to eliminate all detectable VOCs present initially on each medium. Each material sample was analyzed by SPME-GC/MS (same method as that used for samples later described in text) for compound identification and verification of blank background prior to explosive static collection. The gauze pad was held in place using a ring stand placed approximately 2 inches above the sample (Figure 1). Volatiles were collected for different time ranges utilizing a passive non-contact method to determine the optimal collection time. After each collection, the gauze pads were transferred to sterilized $40 \mathrm{~mL}$ clear glass screw top vials with PTFESilicone septa obtained from Supelco (Bellefonte, PA, USA). $60 \mu \mathrm{m}$ polydimethylsiloxane (PDMS) SPME fibers obtained from Supelco (Bellefonte, PA, USA) was the fiber chemistry selected to extract the VOCs from the headspace of the vials containing the collected samples. This specific fiber type was chosen because it is recommended for the extraction of high polar volatiles and semi-volatiles at trace levels [33]. Polydimethylsiloxane (PDMS) SPME fibers, which were the choice for this experimental procedure, are an absorbent fiber type which display a greater capacity and a wider linear range. The SPME fibers were conditioned as recommended by the manufacturer $\left(30 \mathrm{~min}\right.$ at $\left.250^{\circ} \mathrm{C}\right)$ using the injection port of the GCMS prior to use. For the extraction of VOCs, the fiber was injected through the septum and exposed approximately $1.0 \mathrm{~cm}$ above the sample at $56{ }^{\circ} \mathrm{C}$ for the optimized time followed by desorption by GC-MS and/or GC-ECD.

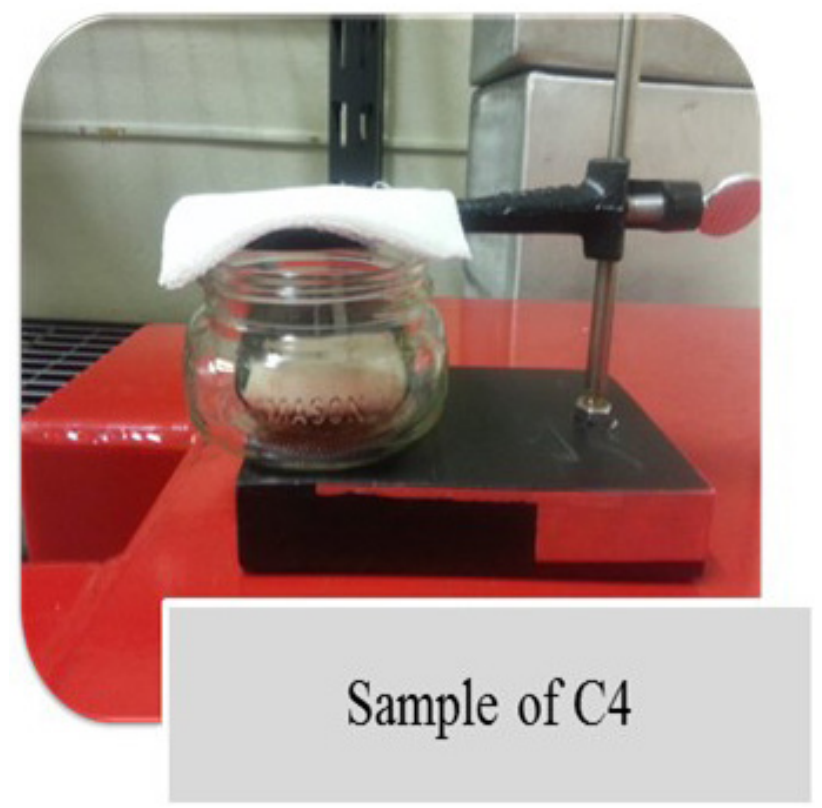

Figure 1: Static Collection of C4 explosive Material

\section{SPME Extraction and Instrumental Analysis of the Extracted VOCs}

VOCs extracted from the headspace of C4 explosive material and single based smokeless powder were determined through SPME followed by desorption into GC-MS and/or GC-ECD to produce a comprehensive screening method that was optimized for the detection of the signature explosive volatiles. The optimal extraction from the headspace of $\mathrm{C} 4$ explosive was found to reach equilibrium extraction time after $30 \mathrm{~min}$ at $56{ }^{\circ} \mathrm{C}$. All samples were heated in a hot plate at $56{ }^{\circ} \mathrm{C}$ during the extraction process. Heating the sample increases the vapor phase concentrations of the compounds found within the matrix, in this case the explosive odor signature. An increase in temperature during the extraction enhances the diffusion of analytes toward the fiber. Thus, in headspace SPME, the temperature helps in the transfer of analytes to the headspace. By increasing the vapor pressure of the analytes, enough energy is supplied to the sample for the compounds to dissociate from the collection medium. An extraction temperature optimization demonstrated that when comparing room temperature, $37{ }^{\circ} \mathrm{C}$ and $56{ }^{\circ} \mathrm{C}$, an enhanced collection of target analyte was achieved in the same amount of time at the higher temperature. For the chromatographic separation, an Agilent 6890 Series GC system was used. The 6890 GC was equipped with front and rear split/splitless injection ports, the front injection port was fitted with an HP5 $30 \mathrm{~m}, 0.25 \mathrm{~mm}$ i.d., $25 \mu \mathrm{m}$ capillary column and the rear injection port was fitted with a RTX TNT $6 \mathrm{~m}$, $0.53 \mathrm{~mm}$ i.d., $1.5 \mathrm{um}$ film thickness Restek (Bellefonte, PA) Rtx ${ }^{\oplus}$ TNT for explosives analysis. The front injection port was held at $265^{\circ} \mathrm{C}$ with a pressure of $7.00 \mathrm{psi}$ and $5 \mathrm{~min}$ SPME desorption. The GC oven temperature was programmed at a $40{ }^{\circ} \mathrm{C}$ hold for 4 min, then heating at $10^{\circ} \mathrm{C} / \mathrm{min}$ up to $300^{\circ} \mathrm{C}$ and held for $2 \mathrm{~min}$ for a total analysis time of $32 \mathrm{~min}$. Helium was the carrier gas at a flow rate of $1 \mathrm{~mL} / \mathrm{min}$ at an average velocity of $37 \mathrm{~cm} / \mathrm{sec}$. The analysis was conducted under splitless mode. The MS was operated in electron ionization (EI) full scan mode from 45 to $500 \mathrm{amu}$, with a 4 minute solvent delay. 
For the analysis of single based smokeless powder, SPME extraction of samples was optimized to reach equilibrium after $21 \mathrm{hr}$ at $56{ }^{\circ} \mathrm{C}$. The rear injection port was connected to a $\mu \mathrm{ECD}$ for explosives analysis. The rear injection port was held at $265^{\circ} \mathrm{C}$ with a 5 min SPME desorption. The oven program was set initially for $2 \mathrm{~min}$ at $80^{\circ} \mathrm{C}$ followed by $25^{\circ} \mathrm{C} / \mathrm{min}$ ramp to $300{ }^{\circ} \mathrm{C}$ with a $5 \mathrm{~min}$ hold for a total run of $15.80 \mathrm{~min}$. Analysis was conducted under splitless mode with a solvent delay of $0.5 \mathrm{~min}$. The detector was held at $320^{\circ} \mathrm{C}$ with anode purge and the carrier was Helium at $15 \mathrm{~mL} / \mathrm{min}$ with a Nitrogen $60 \mathrm{~mL} / \mathrm{min} \mathrm{makeup}$ in the ECD.

Prior to the extraction of each collected sample, appropriate fiber blanks were extracted and desorbed using the same sample method to monitor cross-contamination from previous samples. Compounds were identified by both comparison to external reference standards and the NIST 98 mass spectral reference library. To quantify the amount of compounds being extracted by the SPME fiber, an external calibration was performed using a standard mixture of 2E1H and DMNB with concentrations from 0.5-100 ppm and standard of 2,4-DNT with concentrations from 0.1-2 ppm on the $\mu \mathrm{ECD}$. For the target volatiles $2 \mathrm{E} 1 \mathrm{H}$ and $\mathrm{DMNB}$, the calibration curve range between $0.5-100 \mathrm{ppm}$ demonstrates the fiber capacity to extract target analyte at not only trace concentrations but a higher concentration reaching 100ppm without losing linearity as was observed with the linear dynamic range coefficients of $>0.98$ throughout the study. In order to approximate the amount of VOCs extracted by the SPME fiber, the slope of the line obtained in the calibration curve was used as a response factor for each of the analyzed compounds.

\section{Results/Discussion}

\section{Static Collection of VOCs from C4 Explosive Material}

Static collection of volatiles from C4 was performed indoors at $23.8{ }^{\circ} \mathrm{C}$ with a relative humidity of $77.2 \%$. All static extractions were performed in triplicate. After gauze pads were exposed to $98 \mathrm{~g}$ of $\mathrm{C} 4$, from the $\mathrm{C} 4,2 \mathrm{E} 1 \mathrm{H}$ and DMNB were collected. The amount of volatiles increased over time until 15 and $30 \mathrm{~min}$ where the amount of 2E1H started decreasing (Figure 2). This means that during sampling procedures $2 \mathrm{E} 1 \mathrm{H}$ was quickly released from the $\mathrm{C} 4$ and transferred onto the gauze with minor headspace loss, allowing $82.7 \pm 7.75 \mathrm{ng}$ to be collected with the least relative standard deviation (\%RSD value of 16.2). On the other hand, the greatest collection of DMNB was obtained when the gauze pad was exposed to the odor source for 30 min, then decreasing over time (Figure 2). The average mass collected for DMNB was $125 \pm 10.1 \mathrm{ng}$ with a percent relative standard deviation value of 13.9. The longer static collection time required for $\mathrm{DMNB}$ detection when compared with $2 \mathrm{E} 1 \mathrm{H}$ may be explained by the fact that DMNB has lower volatility which makes this target odorant less available within the available headspace (Table 1).

\begin{tabular}{|c|c|c|c|c|c|c|}
\hline & $\begin{array}{l}\text { Explosive } \\
\text { Class }\end{array}$ & Explosive & Type of Material & $\begin{array}{c}\text { Molecular } \\
\text { Weight (amu) }\end{array}$ & $\begin{array}{c}\text { Vapor Pressure at } \\
25^{\circ} \mathrm{C} \text { (Torr) }\end{array}$ & $\begin{array}{l}\text { Chemical } \\
\text { Structure }\end{array}$ \\
\hline 1. & $\begin{array}{l}\text { Aliphatic } \\
\text { nitro }\end{array}$ & $\begin{array}{c}\text { DMNB } \\
\text { 2,3-Dimethyl- } \\
\text { dinitrobutane }\end{array}$ & $\begin{array}{l}\text { Tagging agent/ } \\
\text { detecting agent } \\
\text { for plastic bonded } \\
\text { explosives (PBX) }\end{array}$ & 176.17 & $2.1 \times 10^{-3}$ & \\
\hline \multirow{2}{*}{2.} & \multirow{2}{*}{$\begin{array}{l}\text { Aromatic } \\
\text { nitro }\end{array}$} & $\begin{array}{c}\text { DNT } \\
\text { 2,4-Dinitrotoluene }\end{array}$ & Plasticizer & 182.14 & $4.1 \times 10^{-7}$ & \\
\hline & & $\begin{array}{c}\text { TNT } \\
\text { 2,4,6-Trinitrotoluene }\end{array}$ & $\begin{array}{l}\text { Military, secondary } \\
\text { explosive }\end{array}$ & 227.13 & $9.1 \times 10^{-9}$ & \\
\hline 3. & $\begin{array}{l}\text { Nitrate } \\
\text { ester }\end{array}$ & $\begin{array}{c}\text { NG } \\
\text { Trinitroglycerin }\end{array}$ & $\begin{array}{l}\text { Active ingredient in } \\
\text { the manufacture of } \\
\text { explosives }\end{array}$ & 227.09 & $6.4 \times 10^{-7}$ & \\
\hline \multirow{2}{*}{4.} & \multirow{2}{*}{$\begin{array}{l}\text { Nitro } \\
\text { amine }\end{array}$} & $\begin{array}{c}\text { RDX } \\
\text { Trinitro- } \\
\text { triazacyclohexane }\end{array}$ & $\begin{array}{l}\text { Military, secondary } \\
\text { explosive }\end{array}$ & 222.12 & $4.8 \times 10^{-12}$ & \\
\hline & & $\begin{array}{c}\text { HMX } \\
\text { Tetranitro- } \\
\text { tetrazacyclooctane }\end{array}$ & $\begin{array}{l}\text { Military, secondary } \\
\text { explosive }\end{array}$ & 296.16 & $2.3 \times 10^{-17}$ & $0^{=N_{-}^{+}}$ \\
\hline
\end{tabular}




\begin{tabular}{|c|c|c|c|c|c|c|}
\hline & $\begin{array}{c}\text { Explosive } \\
\text { Class }\end{array}$ & Explosive & Type of Material & $\begin{array}{c}\text { Molecular } \\
\text { Weight }(\mathbf{a m u})\end{array}$ & $\begin{array}{c}\text { Vapor Pressure at } \\
\mathbf{2 5} \mathbf{5}^{\circ} \mathbf{C} \text { (Torr) }\end{array}$ & $\begin{array}{c}\text { Chemical } \\
\text { Structure }\end{array}$ \\
\hline $\mathbf{5 .}$ & $\begin{array}{c}\text { Fatty } \\
\text { alcohol }\end{array}$ & $\begin{array}{c}\text { 2E1H } \\
\text { 2-ethyl-1-hexanol }\end{array}$ & $\begin{array}{c}\text { Additive in plastic } \\
\text { explosives }\end{array}$ & 130.22 & $1.3 \times 10^{-1}$ & \\
\hline
\end{tabular}

Table 1: Some properties of explosives and target volatiles $[4,22,34]$

As depicted in Figure 2, after 60 min there is no significant difference in the amount of target VOCs collected from C4; indicating that after this time saturation was reached and regardless of how long the absorbent gauze material is exposed to the representative volatile, only a certain amount of the odor is retained. These results show that equilibrium has been reached during the extraction process.

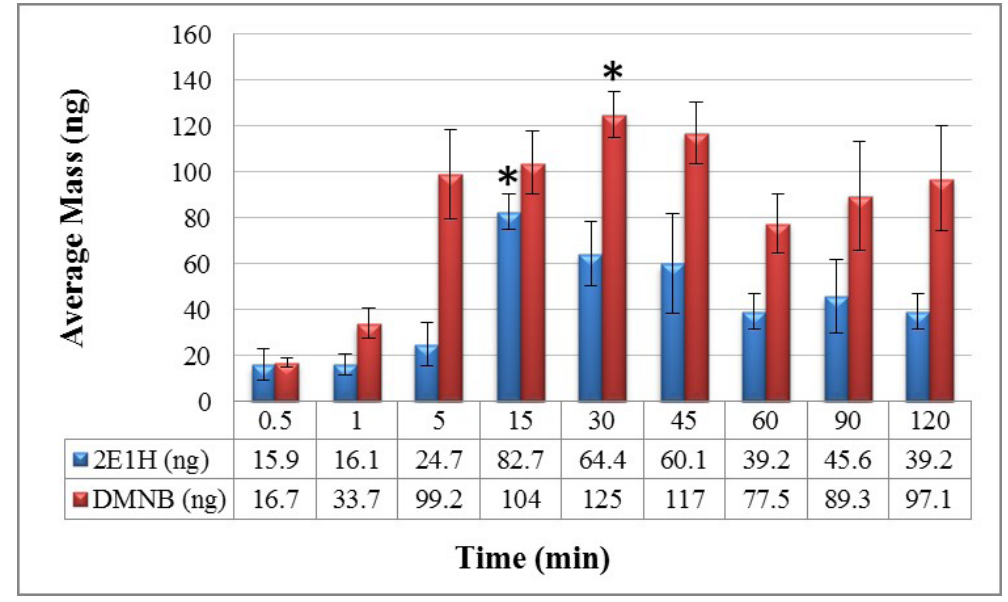

\footnotetext{
* Indicates optimal collection time for target volatile

Figure 2: Average mass collected of $2 \mathrm{E} 1 \mathrm{H}$ and $\mathrm{DMNB}$ from $\mathrm{C} 4$ by static mode over time
}

Analysis of variance (ANOVA) was employed to determine whether or not there was significant difference between the amounts of volatiles collected from $\mathrm{C} 4$ at any time. ANOVA showed significant difference between the amounts collected at time intervals of $0.5,1$, and 5 min when compared with time intervals from 15 through 120 minutes. But when intervals of $0.5,1$, and 5 minutes were compared to each other, ANOVA showed no significant difference. The same result was obtained for comparison of time intervals between $15 \mathrm{~min}$ through $120 \mathrm{~min}$. On the other hand, ANOVA for DMNB collection in static mode, showed significant difference at 0.5 and $1 \mathrm{~min}$ time intervals when compared with the others. However, there was no significant difference when compared to each other. Also, no significant difference was shown when time intervals from 5 min through 120 min were compared to each other.

In Figure 3, a total ion chromatogram overlay of one sample of $\mathrm{C} 4$ showing both target odorants: $2 \mathrm{E} 1 \mathrm{H}$ and DMNB obtained by static collection at 15 and 30 minutes is shown.

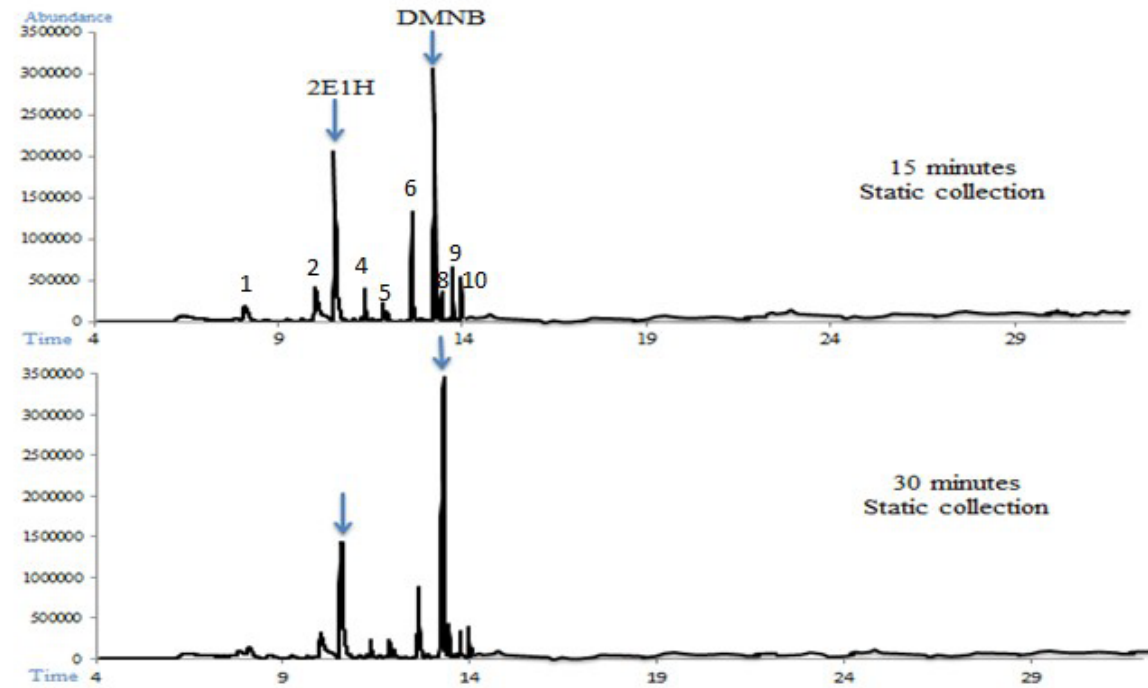

(1) Cyclohexanone, (2) Cyclotetrasiloxane, (3) 2E1H, (4) Undecene, (5) Nonanal, (6) Benzoic acid, (7) DMNB, (8) Decanal, (9) Nonadecane, (10) Tetradecane Figure 3: GC-MS chromatogram of C4 collected at 15 and 30 minutes (optimal collection times for 2E1H and DMNB respectively) 


\section{Static Collection of VOCs from Single Based Smokeless Powder}

Static collection of samples from single based smokeless powder was performed indoors $\left(22.4{ }^{\circ} \mathrm{C}\right.$ with a relative humidity of 46.5\%). As seen in Figure 4, the results show that at 0.5, 1 and 5 minutes static collection of 2,4-DNT is minimal. After 5 minutes, collection of the odorant starts increasing until the 30 minutes where a maximum was reached. For the remaining time, collection of 2,4-DNT remains similar.

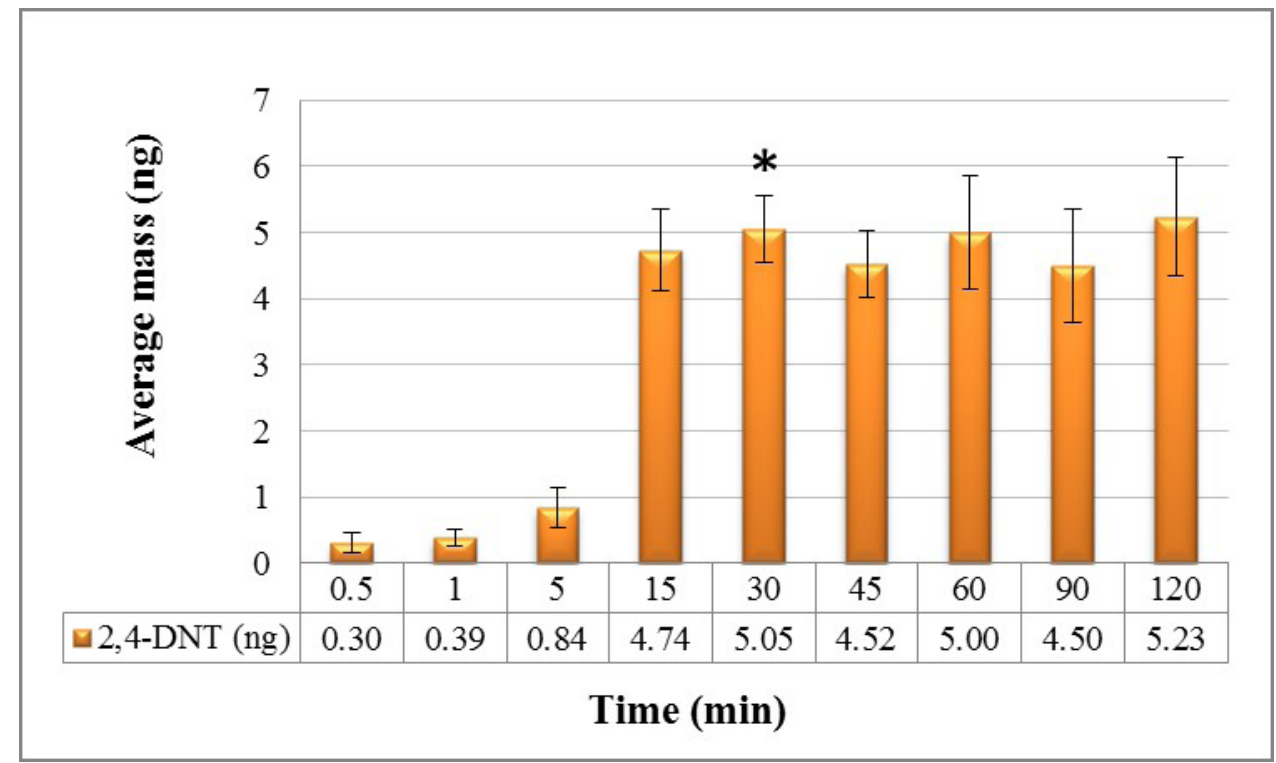

* Indicates optimal collection time for target volatile

Figure 4: Average mass collected of 2, 4-DNT from single based smokeless powder by static mode over time

The maximum amount of 2,4-DNT collected from $25 \mathrm{~g}$ of single based smokeless powder was $5.23 \pm 0.89 \mathrm{ng}$. Based on the values of the relative standard deviation (\%RD), the least variation between samples was obtained at 30 min when compared with the others. Since equilibrium was reached at $30 \mathrm{~min}$, and the percent relative standard deviation was the lowest; it was concluded that optimal static collection time for 2,4-DNT from single based smokeless powder is $30 \mathrm{~min}$ in which an average mass collected is $5.05 \pm 0.51 \mathrm{ng}$. In Figure 5, a chromatogram of one sample of single based smokeless powder obtained at the optimal static collection time of $30 \mathrm{~min}$ is shown.

ANOVA was conducted to determine any significant difference between the amounts collected at each time interval. ANOVA revealed significant differences in the amounts collected after 0.5, 1 and 5 min when compared with time intervals between 15 through $120 \mathrm{~min}$. But when 0.5, 1, and 5 min were compared to each other, ANOVA showed no significant difference. The same result was obtained for comparison of time intervals between 15 through $240 \mathrm{~min}$. The results obtained with 2,4-DNT from single based smokeless powder demonstrate the trapping capability of this volatile within the collection medium (gauze pads) for a specific time during static collection.

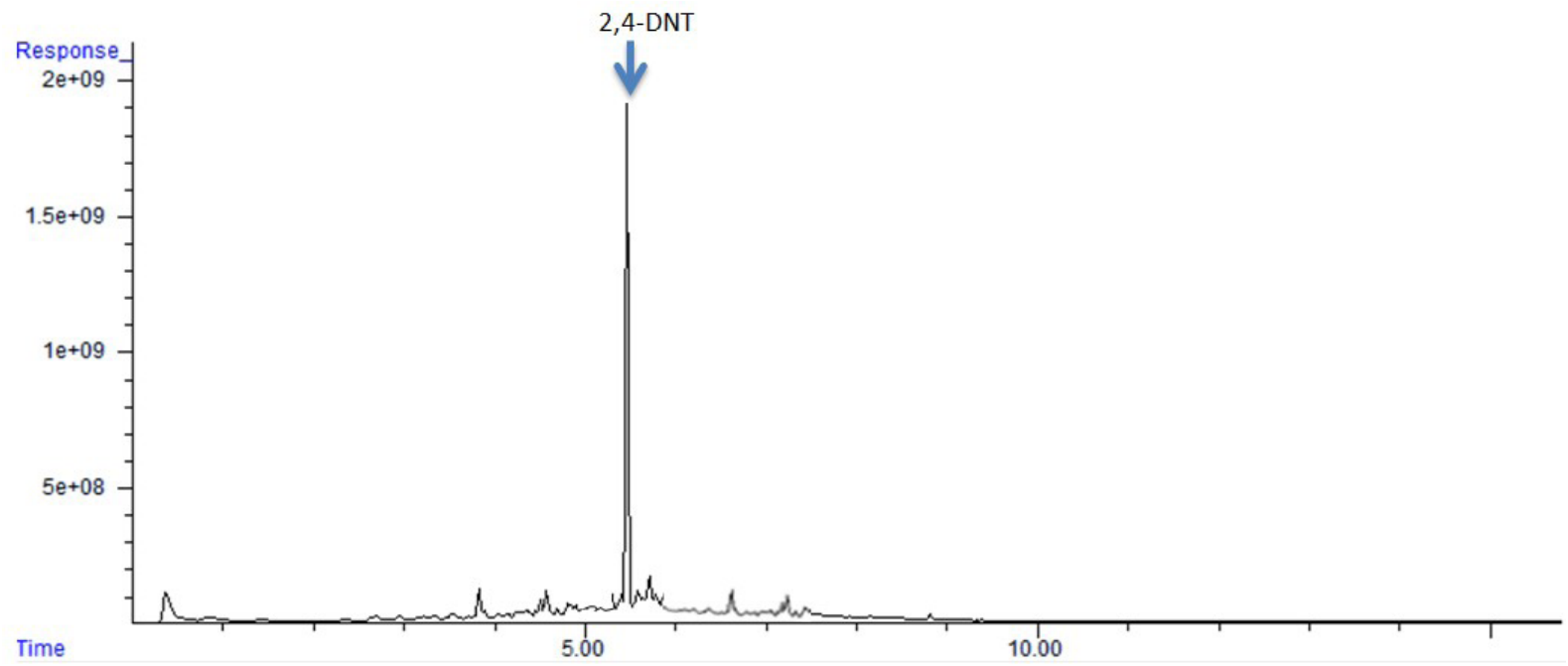

Figure 5: GC-ECD chromatogram of single based smokeless powder sample collected at the optimal static collection time of 30 minutes 


\section{Conclusions}

In order to maintain effective explosive canine detection proficiency, it is recommended to perform routine training of canines in the field. Since transportation and storage of explosives typically used in training requires specific handling and precautions, sustained training is limited. Hence, the need for developing non-explosive training aids that do not have these requirements an area of high research priority. Static collection of volatiles from different explosives can simplify the use of real material by providing reliable training aids which can be used in the development of effective canine team training. It was the purpose of this study to present a static collection method for the extraction of volatiles released from real explosive material onto a gauze pad adsorbent material. The collection of volatiles emitted from any source strongly depends on the concentration of volatiles in the headspace, the degree of confinement, as well as the volatility of the compounds. This sampling method is simple and practical by utilizing, mason jars $(8 \mathrm{oz})$ to concentrate volatile emissions and to prevent direct contact and contamination to the odor source. Military personnel are able to quickly gather explosive volatiles and prepare training aids that are on routinely encountered in the field. The results obtained show that static collection method has proven to be effective in the collection of target volatiles onto an adsorbent material. Therefore, it can be said that static collection of volatiles is a feasible approach for the successful creation of useful and non-hazardous training aids that can serve as a remedy to the drawbacks when using and transporting real explosive materials for canine training. This collection method not only will avoid any exposure risks to canine teams, but will offers law enforcement personnel the feasibility to create training aids on-site guaranteeing the collection of target explosive odor volatiles for subsequent canine training. Continuing research with practical canine behavior testing is an area of ongoing study to provide the usefulness of the prepared canine training aids in practical field settings and evaluate their utility and performance. Factors that are an area of active study include shelf life of the collected samples and a further understanding of their persistence under various storage containment systems. Only through the efficient collection and proper storage will these potential training aids offer their maximum utility for enhance canine training.

\section{Acknowledgements}

The authors would like to thank Dr. Howard Holness for his guidance. Additionally, acknowledge the Technical Scientific Working Group (TSWG) for financial support of this research as well as Metro Dade K9 facility and City of Miami Police Department for facilitating access to explosive material.

\section{References}

1. Lefferts MJ, Castell MR (2015) Vapour sensing of explosive materials. Anal Meth 7: 9005-17.

2. Leitch O, Anderson A, Kirkbride KP, Lennard C (2013) Biological organisms as volatile compound detectors: A review. Forensic Sci Int 232: $92-103$.

3. Marshall M, Oxley J (2011) Aspects of Explosive Detection. Elsevier Press.

4. Ewing RG, Waltman MJ, Atkinson DA, Grate JW, Hotchkiss PJ (2013) The vapor pressures of explosives. TrAC 42: 35-47.

5. Grate JW, Ewing RG, Atkinson DA (2012) Vapor-generation methods for explosives-detection research. TrAC 41: 1-13.

6. Senesac L, Thundat TG (2008) Nanosensors for trace explosive detection. Mat Today 11: 28-36.

7. Singh S (2007) Sensors- An effective approach for the detection of explosives. J Haz Mat 144: 15-28.

8. Bielecki Z, Janucki J, Kawalec A, Mikolajczyk J, Palka N, et al. (2012) Sensors and systems for the detection of explosive devices - an overview. Metro Meas Syst 19: 3-28.

9. Prada PA, Rodriguez MC (2016) Demining Dogs in Colombia - A Review of Operational Challenges, Chemical Perspectives, and Practical Implications. Sci Justic http://dx.doi.org/10.1016/j.scijus.2016.03.002.

10. Williams M, Johnston JM (2002) Training and maintaining the performance of dogs (Canis familiaris) on an increasing number of odor discriminations in a controlled setting. Appl. Anim Behav Sci 78: 55-65.

11. Johnston JM, Williams M, Waggoner LP, Edge CC, Dugan RE, et al. (1998) Canine detection odor signatures for mine-related explosives. Pro PIE 3392: 490501 .

12. Harper RJ, Furton KG (2011) Biological detection of explosives. Counterterrorist Detection. Techn Explo 395.

13. Lazarowski, L, Dorman DC (2014) Explosives detection by military working dogs: Olfactory generalization from components to mixtures. App Anil Beh Scie 15: 84-93.

14. Sandercock PM (2008) Fire investigation and ignitable liquid residue analysis-A review 2001-2007. Forensic Sci Inter 176: 93-110.

15. Furton KG, Harper R (2004) Detection of Ignitable Liquid Residues in Fire Scenes Accelerant Detection Canine (ADC) Teams and other Field Tests, in Advances in Forensic Science Techniques: Interpretation of Fire Scene Evidence, CRC Press, Boca Raton, FL.

16. Furton KG, Hsu Y, Luo T, Wang J, Rose S (1997) Odor signatures of cocaine analyzed by GC/MS and threshold levels of detection for drug detection canines. Current Topics in Forensic Science Meeting International Association of Forensic science 14: 329-32.

17. Macias MS, Harper RJ, Furton KG (2008) A comparison of real versus simulated contraband VOCs for reliable detector dog training utilizing SPME-GC-MS. Amer Biotech Lab 40: 26-7.

18. Curran AM, Prada PA, Furton KG (2010) Canine human scent identifications with post-blast debris collected from improvised explosive devices. Forensic Sci Inter 199: 103-8.

19. Prada PA, Curran AM, Furton KG (2014) Human Scent Evidence. CRC Press

20. Law Enforc (1994) Legal Rev 23: 6. 
21. Furton KG, Myers LJ (2001) The Scientific Foundations and Efficacy of the Use of Canines as Chemical Detectors for Explosives. Talanta 54: 487-500.

22. Harper RJ, Almirall JR, Furton KG (2005) Identification of Dominant Odor Chemicals Emanating from Explosives for Use in Developing Optimal Training Aid Combinations and Mimics for Canine Detection. Talanta 67: 313-7.

23. Yinon J (2002) Field detection and monitoring of explosives. Trends Anal Chem 21: 292-301.

24. Lorenzo N, Wan T, Harper RJ, Hsu YL, Chow M, et al. (2003) Laboratory and Field Experiments Used to Identify Canis Familiaris Active Odor Signature Chemicals from Drugs, Explosives, and Humans. Anal Bioanal Chem 376: 1212-24.

25. Harper RJ, Almirall JR, Furton KG (2004) Improving the Scientific Reliability of Bio-Logical Detection of Explosives by Canis Familiaris through Active Odor Signatures and Their Implications, in: Proceedings of the 8th International Symposium on the Analysis and Detection of Explosives (ISADE), Ottawa, Canada. 26. Stefanuto PH, Perrault KA, Focant JF, Forbes SL (2015) Fast Chromatographic Method for Explosive Profiling. Chrom 2: 213-24.

27. Lai H, Leung A, Magee M, Almirall JR (2010) Identification of Volatile Chemical Signatures from Plastic Explosives by SPME-GC/MS and Detection by Ion Mobility Spectrometry. Anal and Bioanal Chem 396: 2997-3007.

28. Joshi M, DelgadoY, Guerra P, Lai H, Almirall JR (2009) Detection of Odor Signatures of Smokeless Powders Using Solid Phase Microextraction Coupled To an Ion Mobility Spectrometer. Forensic Sci Inter 188: 112-8.

29. Perr JM, Furton KG, Almirall JR (2005) Solid Phase Microextraction Ion Mobility Spectrometer Interface for Explosive and Taggant Detection. J Sep Sci 28: 177-83.

30. Edge CC, Gibb J, Dugan R (1998) Comparative study of the vapor analytes of trinitrotoluene (TNT). Proce of SPIE 3575: 282-90.

31. Ensminger JJ (2011) Police and Military Dogs: Criminal Detection, Forensic Evidence, and Judicial Admissibility, 1st ed, New York, USA: CRC Press 221-34.

32. Scientific Working Group on Dog \& Orthogonal detector Guidelines. Approved guidelines.

33. Pawliszyn J (2000) Theory of solid-phase microextraction. J Chromatogr Sci 38: 270-8.

34. Cummings C (2004) Detection of explosives vapor using the Nomadics FIDO sensor. Proceedings of the 1st Olfactory-Based Systems for Security Applications meeting (OBSSA), London, UK.

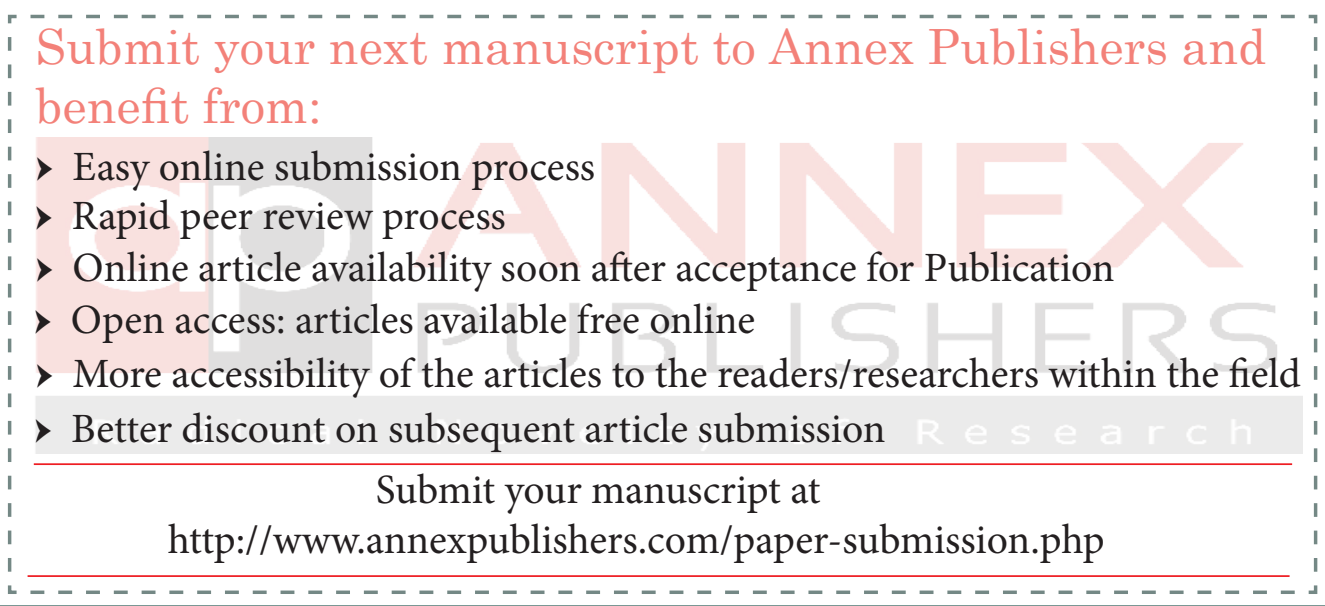

